\title{
UMA ABORDAGEM DE ENGENHARIA DE SISTEMAS PARA GESTÃO DE INOVAÇÃO EM UMA EMPRESA DE MEDICINA DIAGNÓSTICA
}

\author{
Amanda Ferri Curti (acurti@ufabc.edu.br) - Programa de Pós Graduação em Engenharia e Gestão de \\ Inovação, Universidade Federal do ABC - UFABC \\ Luciana Pereira (luciana.pereira@ufabc.edu.br) - Programa de Pós Graduação em Engenharia e Gestão \\ de Inovação, Universidade Federal do ABC - UFABC \\ Anderson Orzari Ribeiro (anderson.ribeiro@ufabc.edu.br) - Programa de Pós Graduação em Engenharia \\ e Gestão de Inovação, Universidade Federal do ABC - UFABC
}

\section{RESUMO}

Esse artigo é resultado de um estudo realizado em uma empresa de medicina diagnóstica brasileira, reconhecida por incorporar o estado da arte das pesquisas e transformá-lo em produtos e serviços. Desde a criação de um novo conceito de serviço até sua disponibilização para o mercado é discorrido um complexo processo de desenvolvimento, que depende da interação de múltiplos atores. A integração entre esses atores pode ser determinante para o sucesso da implementação de uma inovação. A literatura apresenta diversas soluções organizacionais para geração de inovação, além de outros mecanismos, como direcionamento estratégico e ferramentas de design. Esse artigo questiona se uma ferramenta de engenharia pode ser complementar a gestão de inovação, garantindo a integração necessária entre as diversas unidades de negócio envolvidas no lançamento de uma inovação. Para responder a essa pergunta, faz-se uso de uma abordagem de engenharia de sistemas, a aplicação do método de engenharia de sistemas no modelo de ciclo de vida do sistema. Os resultados demonstraram que a ferramenta traz uma visão instrutiva do processo de design e desenvolvimento de um conceito inovador de serviço, podendo ser complementar à gestão de inovação. Sugere-se que a metodologia possa ser projetada para outras empresas, e tipos de inovação.

Palavras-chave: inovação em saúde, organização ambidestra, engenharia de sistemas, design de serviços.

Área: Inovação e a gestão do desenvolvimento de produtos e serviços em empresas no Brasil

\section{INTRODUÇÃO}

A economia global é um sistema complexo e dinâmico que exige uma grande capacidade de resposta das empresas frente às inovações do mercado. As relações nesse sistema, interconectado e interativo, aumentam a capacitação tecnológica e gerencial necessárias para melhorar produtos e serviços, que são essenciais para a sobrevivência e o sucesso das empresas. A literatura apresenta diversas soluções de design organizacional para a geração de inovação, além de outros mecanismos para viabilizar a ambidestria organizacional, ou seja, a capacidade das empresas se adaptarem para explorarem seus negócios existentes e o mercado. As pesquisas existentes, entretanto, não explicam as etapas e os processos pelos quais as unidades de negócio relacionadas à inovação e as unidades que fazem a atividade fim de uma empresa colaboram durante a execução de um novo produto ou serviço. 
Para contribuir com essa lacuna, esse projeto levanta a seguinte questão: uma ferramenta de engenharia pode ser complementar a de gestão de inovação, para garantir a integração necessária entre as diversas unidades de negócio envolvidas no lançamento de uma inovação?

Para o estudo, foi selecionada uma empresa brasileira de medicina diagnóstica, devido ao comportamento de constantes mudanças do mercado de saúde, e à estrutura organizacional ambidestra da empresa. Inovação em medicina diagnóstica engloba novas tecnologias aplicadas a produtos e serviços utilizados para diagnosticar, monitorar, prevenir e indicar tratamento aos pacientes. Os resultados desse processo tem portanto alto valor pois impactam no prolongamento da vida ativa e na limitação de custos do cuidado de pacientes com doenças crônicas, evitando hospitalização e o uso de tratamentos ineficientes (MARRONE, 2015).

O setor de saúde é caracterizado como altamente fragmentado, fortemente baseado na ciência e alta tecnologia, e possui um rápido ciclo de inovação (CHAVES E ALBUQUERQUE, 2006). Fatores como os conflitantes objetivos dos vários atores da cadeia; as particularidades do financiamento de saúde; e a rígida regulamentação do setor tornam, entretanto, o processo para lançamento dessas inovações complexo e crítico (HERZLINGER, 2006; CURTIS e SCHULMAN, 2006).

Em termos metodológicos, esse estudo adapta a aplicação do método de engenharia de sistemas ao modelo de ciclo de vida do sistema para os processos de design e desenvolvimento de novos serviços de medicina diagnóstica. Os dados para análise foram obtidos através de observação direta, documentos publicados, e entrevistas semi-estruturadas a colaboradores que participaram da implantação de uma amostra de novos serviços selecionada.

Esse trabalho parte da hipótese que, no geral, as empresas enxergam seus processos de inovação como um funil, uma "caixa preta", que leva uma ideia ao desenvolvimento, mas não conhecem o passo-a-passo que permite a sua implantação. Esse gap de conhecimento por parte da empresa, faz com que os gestores de inovação não conheçam previamente quais os atores envolvidos no processo e como efetivamente podem ser integrados para colaborar na execução do projeto. Assim, transformar um conceito em um novo produto ou serviço se torna uma tarefa cada vez mais complexa e lenta. O objetivo é propor então uma ferramenta conceitual de engenharia que possa ser aplicada no design e desenvolvimento de novos serviços, para trazer aos gestores uma visão instrutiva do processo geral de desenvolvimento, que poderá orientá-los a transformar um conceito em um novo serviço, planejando as etapas necessárias para tal, priorizando atividades e integrando as equipes envolvidas.

Para isso, organizamos esse artigo inicialmente em uma revisão sobre a importância da estrutura operacional da empresa para se adequar a um mercado em constantes mudanças como é o da saúde. Na seção 3 apresentamos os fundamentos metodológicos utilizados para a proposta de coleta e análise dos dados estudados. Por fim, são apresentados alguns dos resultados e conclusões sobre este estudo de caso e suas possíveis projeções para outras empresas com características similares.

\section{ESTRUTURA ORGANIZACIONAL PARA INOVAÇÃO}

Estudos de adaptação organizacional mostraram a importância de ajustes organizacionais para as empresas. Para Lischka (2015), em um ambiente de constantes mudanças, as organizações incompatíveis são eliminadas ao longo do tempo. De acordo com a autora, a literatura sobre estratégia afirma, desde os estudos de Ansoff em 1965, que as empresas de sucesso são aquelas que conseguem alterar sua estratégia de acordo com as mudanças no ambiente. Oliver (2015 apud LISCHKA, 2015), também afirma que alcançar uma vantagem adaptativa é o fator-chave para sustentar a performance de mercado. 
Dentro desse conceito de adaptação, James March apresenta em 1991, os conceitos de exploration e exploitation. March (1991) notou a necessidade de adaptação das empresas para poder explorar tanto seus processos e aptidões existentes, a que o autor chama de exploiting, quanto explorar o mercado para se antecipar às mudanças, a que ele denomina exploring. Para o autor, encontrar um equilíbrio entre exploration e exploitation, é fator essencial para a prosperidade das organizações, uma vez que empresas focadas em exploration sofrem os custos de experimentação e possuem baixo retorno, apresentando muitas ideias não desenvolvidas, enquanto empresas focadas em exploitation ficam presas em uma estabilidade de negócio abaixo do ideal. Tushmann \& O'Reilly (1996) complementam que as empresas que se estruturam e conseguem lidar com as duas competências de forma balanceada são denominadas ambidestras.

Para alcançar a ambidestria são propostos alguns ajustes organizacionais. Segundo Teh (2014), não existe uma estrutura ideal, a estruturação depende do contexto da empresa e de parâmetros definidos em função da estratégia, intensidade e tipo de inovação, havendo assim inúmeras possibilidades de configuração. Tushman e O'Reilly (2013), destacam três abordagens para a estrutura organizacional, consideradas na literatura:

- Ambidestria sequencial: quando a empresa muda a estrutura para alinhá-la à sua estratégia, ora apostando em aproveitar potencialidades de processos atuais, ora prospectando novos processos para atender aos próximos cenários de negócios. Essa estrutura é considerada ineficiente quando a empresa está em um ambiente de rápidas mudanças. Para tal, sugere-se explorar o negócio atual e o futuro simultaneamente;

- Ambidestria simultânea ou estrutural: sugere o estabelecimento de unidades autônomas, com diferentes pessoas, sistemas e processos, para simultaneamente explorar os dois lados da ambidestria. Essas unidades devem estar ligadas por uma estratégia comum, e ter uma liderança capaz de integrá-las e de gerenciar as tensões entre elas;

- Ambidestria contextual: propõe que as organizações devam construir um conjunto de processos que permitam e encorajem os indivíduos a fazerem seus próprios julgamentos sobre como dividir seu tempo exploiting e exploring.

Apesar de terem características diferentes e soarem excludentes, Tushman e O'Reilly (2013) ressaltam que todas as abordagens são potencialmente viáveis e que elas podem também ser combinadas. Os autores sugerem que o ajuste estrutural da organização, alinhado a seus desafios e ao ambiente de mercado, é uma maneira efetiva para as organizações lidarem com os desafios de exploit e explore.

Além de ajustes na estrutura organizacional, outros mecanismos organizacionais são sugeridos para que se alcance a ambidestria, destacando-se: práticas de gestão de pessoas para a inovação, que incentivem a flexibilidade e desenvolvimento; um time sênior e de gestores ambidestros, combinando um perfil mais aberto à inovação a um perfil "redução de custos"; a garantia de autonomia operacional para as diversas divisões de negócio da empresa, com a centralização de decisões estratégicas e financeiras; mecanismos integradores promovendo a comunicação entre áreas; e ajuste cultural, garantindo valores fortes e integrados entre as diversas áreas da empresa. (TEH, 2014; TUSHMAN e O’REILLY, 2004; MARKIDES e CHU, 2009)

\section{METODOLOGIA}

Para responder a pergunta de pesquisa, este artigo utiliza uma abordagem de engenharia de sistemas, mais especificamente, a aplicação do método de engenharia de sistemas no modelo de ciclo de vida do sistema. 
De acordo com Kossiakoff (2011), um programa de desenvolvimento de sistema consiste em um esforço complexo para satisfazer a uma necessidade do cliente, que envolve múltiplas disciplinas, depende do comprometimento de recursos e é conduzido seguindo um "passo a passo". Esse passo-a-passo é denominado "ciclo de vida do sistema".

A abordagem deste trabalho é baseada no modelo de ciclo de vida proposto por Kossiakoff (2011), por se tratar de uma evolução de modelos anteriores aplicados em sistemas militares complexos e sistemas comerciais, e pela visão que o autor propõe de "materialização" do sistema. Segundo o autor, os passos de desenvolvimento de um novo sistema podem ser vistos como uma "materialização" progressiva ordenada, que parte de uma necessidade abstrata e, com a organização e cooperação dos seus elementos, se torna um produto atendendo à necessidade proposta. O modelo pode ser dividido em três grandes fases: desenvolvimento de conceito, desenvolvimento de engenharia e pós-desenvolvimento, conforme demonstrado na figura 1 .

Figura 1- Modelo de ciclo de vida do sistema.

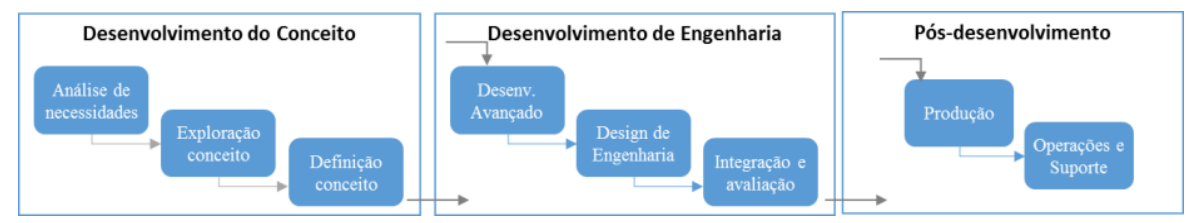

Fonte: traduzido e adaptado de Kossiakoff (2011)

O primeiro estágio no modelo compreende a definição do conceito do sistema, ou seja, as análises e o planejamento necessário para se definir as necessidades do sistema, a viabilidade de implementação e o desenho da arquitetura que melhor atenda às necessidades. Os objetivos principais dessa etapa segundo o autor são: estabelecer que exista uma necessidade ou mercado real para um novo sistema, tecnicamente e economicamente viável; explorar potenciais conceitos; desenhar uma série de requisitos para a performance do sistema; definir as características funcionais; e desenvolver um plano detalhado para as etapas subsequentes de engenharia. Essa etapa se divide em três fases:

- Análise de necessidades: define a necessidade para criação de um novo sistema. Levanta questões como "Existe uma necessidade real para se desenvolver um novo sistema?" e "Existe uma abordagem prática que satisfaça a essa necessidade?";

- Exploração de conceito: examina conceitos potenciais ao responder questões como "O que é necessário para o novo sistema atender às necessidades colocadas?", "Existe ao menos uma abordagem factível, a um custo acessível, para gerar o valor esperado?";

- Definição de conceito: seleção do conceito que alcance o melhor equilíbrio entre características, operacionalização e custos. Para essa fase, é necessário considerar múltiplos conceitos alternativos, para comparar suas características.

A segunda etapa compreende os esforços de engenharia na construção do sistema, objetivando o desenvolvimento de um protótipo que satisfaça os requisitos de performance e segurança e que se demonstre operacionalmente adequado. Essa etapa divide-se em três fases:

- Desenvolvimento avançado: objetiva identificar e reduzir riscos de desenvolvimento, e desenvolver o design do sistema. Modelos experimentais e simulações podem ser utilizados nessa fase para validar os conceitos definidos;

- Design de engenharia: consiste em converter as especificações em um protótipo e refinar o plano de testes e avaliação do sistema;

- Integração e avaliação: consiste em integrar todos os componentes do sistema em um único sistema funcional, avaliando sua operação em um ambiente real controlado. Os 
outputs dessa fase são um guia de especificações para a produção. Nessa etapa é importante simular algumas situações reais para medir as possíveis respostas do sistema e fazer os ajustes necessários antes de lança-lo no mercado.

Por fim, o último estágio do modelo traz as atividades de lançamento do sistema, suporte e solução de problemas. Como o foco desse estudo está no design e desenvolvimento de novos serviços, a fase de pós-desenvolvimento não será contemplada.

Em cada uma das três etapas do ciclo de vida do sistema existem atividades que tendem a se repetir. Esse conjunto de atividades iterativas é denominado por Kossiakoff (2011) como "método de engenharia de sistemas". O método pode ser visto como uma aplicação sistemática de metodologia científica a um sistema complexo de engenharia, e consiste em quatro atividades básicas que são aplicadas sucessivamente: análise de requisitos, definição funcional, definição física e validação de design. Seus principais elementos são representados em um diagrama de fluxo, na figura 2. O diagrama apresenta os inputs provenientes da fase anterior, os inputs externos, e o fluxo de informações entre as etapas. Os blocos retangulares e os círculos representam as etapas do método e as atividades-chave, daquele bloco.

Figura 2 - Diagrama de fluxo do método de engenharia de sistemas.

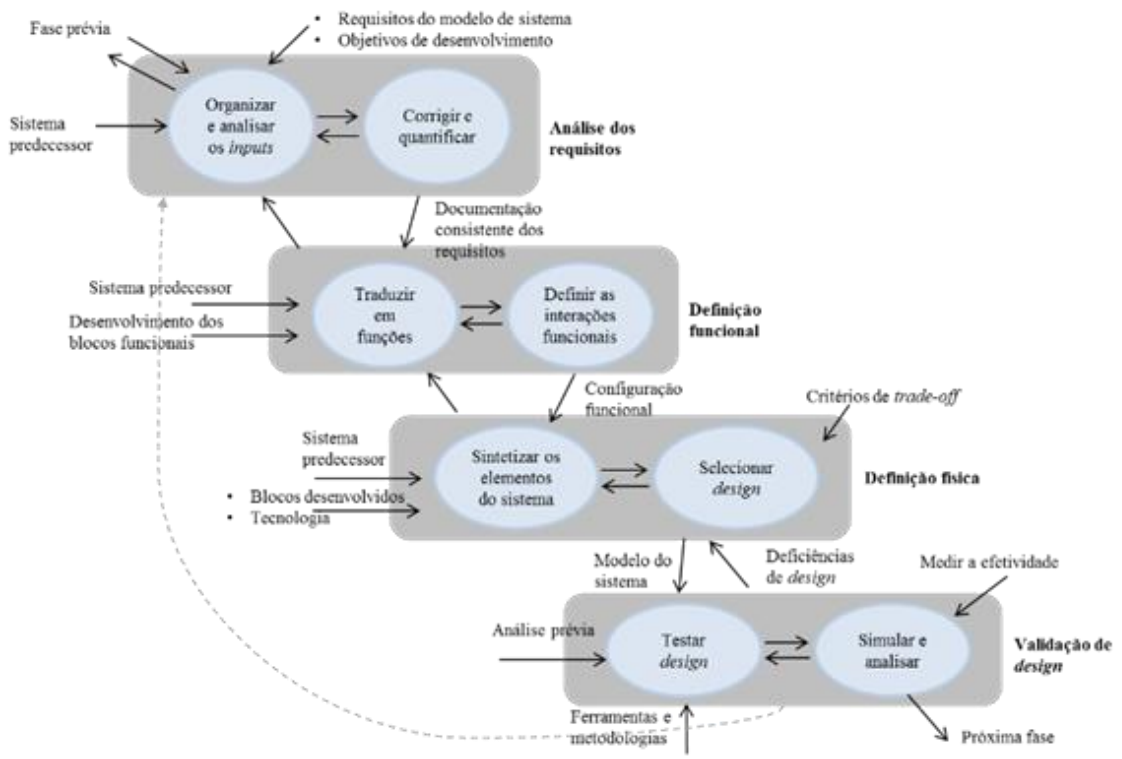

Fonte: traduzido e adaptado de Kossiakoff (2011)

Kossiakoff (2011), ilustra então como o método de engenharia de sistemas pode ser aplicado em fases sucessivas do ciclo de vida do sistema. A tabela 1 apresenta a atividade relacionada a cada uma das quatro etapas do método para cada fase do ciclo de vida do sistema. Conforme o processo avança, mais específica e detalhada é a atividade.

\begin{tabular}{|c|c|c|c|c|c|c|}
\hline & \multicolumn{3}{|c|}{ Desenvokvimento do Conceito } & \multicolumn{3}{|c|}{ Deservolvimento de Engenharia } \\
\hline & Análise de necessidades & $\begin{array}{l}\text { Exploração de } \\
\text { conceito }\end{array}$ & Definição de Conceito & $\begin{array}{c}\text { Desenvolvimento } \\
\text { Avançado }\end{array}$ & $\begin{array}{l}\text { Design de } \\
\text { engenharia }\end{array}$ & Integração e avaliação \\
\hline $\begin{array}{l}\text { Análise de } \\
\text { requisitos }\end{array}$ & Análise de necessidades & $\begin{array}{c}\text { Análise operacional } \\
\text { dos requisitos }\end{array}$ & $\begin{array}{c}\text { Análise da performance } \\
\text { dos requisitos }\end{array}$ & $\begin{array}{l}\text { Análise funcional dos } \\
\text { requisitos }\end{array}$ & $\begin{array}{c}\text { A nalisar os } \\
\text { requisitos de design }\end{array}$ & $\begin{array}{c}\text { Analisar testes e validar } \\
\text { requisitos }\end{array}$ \\
\hline $\begin{array}{l}\text { Definição } \\
\text { funcional }\end{array}$ & $\begin{array}{l}\text { Definir objetivos do } \\
\text { sistema }\end{array}$ & $\begin{array}{l}\text { Definir as funções } \\
\text { dos subsistemas }\end{array}$ & $\begin{array}{c}\text { Desenvolvimento } \\
\text { funci onal - arquitetura, } \\
\text { componentes, funções }\end{array}$ & $\begin{array}{l}\text { Refinar as funcionali dades: } \\
\text { arquitetura, componentes }\end{array}$ & $\begin{array}{c}\text { Definir funções das } \\
\text { peças }\end{array}$ & Definir funções e testes \\
\hline Definição física & $\begin{array}{c}\text { Definir caracteristicas do } \\
\text { sistema, subsi stemas, } \\
\text { tecnologia }\end{array}$ & $\begin{array}{c}\text { Definir conceito do } \\
\text { sistema, visualizar } \\
\text { componentes }\end{array}$ & $\begin{array}{c}\text { Desenvolvimento fisico } \\
\text { - arqui tetura e } \\
\text { componentes }\end{array}$ & $\begin{array}{l}\text { Refinar de senvolvimento } \\
\text { fi sico: arquitetura, } \\
\text { componentes, construcão }\end{array}$ & $\begin{array}{c}\text { Especificar } \\
\text { subcomponentes e } \\
\text { construcão }\end{array}$ & $\begin{array}{l}\text { Definir testes fisicos- } \\
\text { especificar equipamentos } \\
\text { de testes e instalacões }\end{array}$ \\
\hline $\begin{array}{c}\text { Validação de } \\
\text { design }\end{array}$ & $\begin{array}{c}\text { Validação das } \\
\text { necessidades e } \\
\text { viabilidades }\end{array}$ & $\begin{array}{c}\text { Validar os requisitos } \\
\text { operacionais }\end{array}$ & $\begin{array}{c}\text { Avaliar as capacidades } \\
\text { do sistema }\end{array}$ & $\begin{array}{l}\text { Testar e avaliar os } \\
\text { subsistemas criticos }\end{array}$ & $\begin{array}{c}\text { Validar componentes } \\
\text { e construção }\end{array}$ & Testar e validar sistema \\
\hline
\end{tabular}

Fonte: traduzido e adaptado de Kossiakoff (2011) 
A aplicação de método de engenharia de sistemas no ciclo de vida permite, dessa forma, uma visão instrutiva do processo geral de desenvolvimento do sistema, demonstrando quais atividades são realizadas para que o sistema se materialize e progrida de uma necessidade abstrata a um conceito e, por fim, a um sistema validado em produção.

\subsection{Coleta de dados}

Esse estudo foi conduzido em uma empresa de medicina diagnóstica reconhecida por incorporar o estado da arte das pesquisas e transformá-lo em produtos e serviços e que adota como solução de design organizacional a ambidestria simultânea, explorando simultaneamente a inovação e o negócio.

Os dados foram coletados através da análise de documentos da empresa, como Relatório Institucional; instruções de processos e artigos publicados, que trouxeram uma visão geral de estratégia, processos e estrutura de inovação; e através de observação direta por um período de dois anos, onde participou-se da idealização e implantação de inovações.

Para complementar a pesquisa, e partindo de conceitos de Engenharia de Sistemas, que sugerem que a maioria dos sistemas evolui de um sistema predecessor, foi selecionada uma amostra de cinco projetos de novos serviços já implantados pela empresa. Dessa forma, é possível mapear as etapas do fluxo que deveriam ser mantidas no processo, e aquelas que poderiam ser melhoradas. Todos os projetos selecionados trazem novos conceitos de serviço, são de diferentes graus de inovação e foram desenvolvidos por áreas distintas da empresa. Os dados dessa etapa foram obtidos por meio de entrevistas semi-estruturadas aos líderes responsáveis pela implantação dos projetos e também a colaboradores que participaram do desenvolvimento desses novos conceitos.

\subsection{Análise e validação dos dados}

Para organizar os dados obtidos nas entrevistas, análises de documentos e observação direta, foram construídos mapas que representassem o processo de desenvolvimento de um novo serviço. Esses mapas contemplaram as macro etapas do processo, as atividades-chave realizadas e os principais atores envolvidos. Os dados obtidos foram então interligados a conceitos de gestão de inovação, ambidestria organizacional e engenharia de sistemas, para avaliar se uma ferramenta de engenharia pode ser complementar a gestão de inovação, a fim de garantir a integração necessária entre as diversas unidades de negócio envolvidas no lançamento de uma inovação.

Partindo dos conceitos de Kossiakoff (2011), o método de engenharia de sistema foi aplicado sobre o "ciclo de vida" de design de serviços, a fim de detalhar os objetivos e entregas principais esperados para cada etapa do método, em cada fase de desenvolvimento da inovação.

Na segunda etapa da análise, foram detalhadas as atividades-chave necessárias para se alcançar os objetivos esperados em cada fase, e identificados os atores envolvidos no processo. Por fim, foi construído o diagrama de fluxo representando a aplicação do método de engenharia de sistemas sobre o processo de design e desenvolvimento de um novo serviço.

Para validar os resultados foi realizada uma triangulação com o referencial teórico e metodológico, os dados coletados, e as informações obtidas por observação direta. A triangulação, permite que múltiplas teorias, métodos e materiais empíricos sejam combinados de modo a se complementar, colocando sob uma mesma perspectiva diferentes aspectos do objeto de estudo. Os resultados obtidos são apresentados na próxima seção. 


\section{RESULTADOS}

Aplicando o método de engenharia de sistemas no ciclo de vida, chegou-se a uma proposta conceitual para design e desenvolvimento de serviços inovadores em medicina diagnóstica, representada na tabela 2. A tabela apresenta, inicialmente, quais perguntas devem ser respondidas em cada etapa do desenvolvimento e pode ser utilizada como uma ferramenta para ordenar as atividades necessárias para o lançamento de um novo conceito no mercado. Ela deve ser lida de cima para baixo, da esquerda para a direita. Cada quadrante representa os objetivos e entregas esperadas para aquela etapa, dentro da fase de desenvolvimento.

\begin{tabular}{|c|c|c|c|c|c|c|}
\hline & \multicolumn{3}{|c|}{ Desew ol imento do Conceito } & \multicolumn{3}{|c|}{ Desenvohimento de E ngenharia } \\
\hline & Análise de necessidades & Exploração de conceito & Definị̌̃ão de Conceito & Desens okvimento Avançado & Design de engenharia & Integração e av aliação \\
\hline \multirow[t]{2}{*}{ Perguntas } & $\begin{array}{c}\text { Existe uma necessidade } \\
\text { real? }\end{array}$ & $\begin{array}{l}\text { Oqua é nacess ário para o } \\
\text { serviço atender às } \\
\text { nacessidades colocadas? }\end{array}$ & \multirow{2}{*}{$\begin{array}{l}\text { Qual conceito garante naior } \\
\text { equilibrio entre a proposta } \\
\text { de valor, a } \\
\text { operacionalização e os } \\
\text { cus tos /inves imento } \\
\text { envolvidos? }\end{array}$} & \multirow{2}{*}{$\begin{array}{l}\text { Como converter as } \\
\text { es pecificações em um } \\
\text { protólipo? }\end{array}$} & \multirow{2}{*}{$\begin{array}{l}\text { Quais os possive is riscos e } \\
\text { oportunidades do serviço? }\end{array}$} & \multirow{2}{*}{$\begin{array}{c}\text { O novo serviço está pronto } \\
\text { para lançamento no } \\
\text { mercado? }\end{array}$} \\
\hline & $\begin{array}{c}\text { Exista uma solvção que } \\
\text { satis faça a essa } \\
\text { necessidade? }\end{array}$ & $\begin{array}{c}\text { Existe uma abordagem } \\
\text { factivel para geraro valor } \\
\text { esperado? }\end{array}$ & & & & \\
\hline Análise de requisitos & $\begin{array}{l}\text { Mapear nacessid ades } \\
\text { (mercad ol ógicas, } \\
\text { Ecnol ógicas, de nagócio) }\end{array}$ & $\begin{array}{c}\text { Mapear os requisitos para } \\
\text { que o serviço atenda as } \\
\text { nacessidades }\end{array}$ & $\begin{array}{c}\text { Mapear requisitos } \\
\text { necessários para estruturar o } \\
\text { serviço }\end{array}$ & $\begin{array}{c}\text { Mapear ambiente e } \\
\text { condiçôs do Teste Piloto }\end{array}$ & $\begin{array}{l}\text { Anal is ar requi sitos para } \\
\text { implantar o Piloto }\end{array}$ & $\begin{array}{l}\text { Análise dos resultad os do } \\
\text { Piloto }\end{array}$ \\
\hline Definição funcional & $\begin{array}{c}\text { Definir a oportunid ade: o } \\
\text { que o novo serviço pretenda } \\
\text { resolver? Qual sua proposta } \\
\text { de valor? }\end{array}$ & $\begin{array}{l}\text { Definir os requisitos esuas } \\
\text { funcionalid ades }\end{array}$ & $\begin{array}{l}\text { Des enhar processos e atores } \\
\text { envol vidos no novo serviço: } \\
\text { como funcionará na prática }\end{array}$ & Detalhar plano do Piloto & Desenvol vimento do Piloto & $\begin{array}{l}\text { Definir parâmetros para } \\
\text { integração do novo serviço }\end{array}$ \\
\hline Definição física & $\begin{array}{c}\text { Definir potenciais conceitos } \\
\text { de serviço que poderiam } \\
\text { capturar a oportunidada } \\
\text { mapeada }\end{array}$ & $\begin{array}{l}\text { Desenhar a estrutura do } \\
\text { novo serviço }\end{array}$ & $\begin{array}{c}\text { Definir a infaes trutura } \\
\text { necessária para viabilizar o } \\
\text { novo serviço }\end{array}$ & $\begin{array}{l}\text { Definir critérios de } \\
\text { avaliação do Pilo to }\end{array}$ & $\begin{array}{l}\text { Lançamento do Piloto em } \\
\text { ambiente control ado }\end{array}$ & $\begin{array}{l}\text { Conduzzir ajus tes naces sários } \\
\text { para implantą̧ão do serviço }\end{array}$ \\
\hline Valilação de design & $\begin{array}{c}\text { Validar quais conceitos têm } \\
\text { maior potencial de atender } \\
\text { às necessidades, para serem } \\
\text { explorados }\end{array}$ & $\begin{array}{l}\text { Validar requisitos e } \\
\text { proposta de estrutura do } \\
\text { novo serviço }\end{array}$ & $\begin{array}{c}\text { Validar viabilid ade técrica } \\
\text { e económica do conceit to } \\
\text { proposto }\end{array}$ & $\begin{array}{l}\text { Validação da cons tryc ão } \\
\text { para inicio da fase de tas tas }\end{array}$ & $\begin{array}{c}\text { Avaliação de resultados do } \\
\text { Piloto seguindo critérios pré. } \\
\text { definidos }\end{array}$ & Aprovação para lanç ament \\
\hline
\end{tabular}

Fonte: autor.

Assim, é possível acompanhar a progressão do desenvolvimento do novo conceito, desde a análise de necessidades, até a integração do protótipo e aprovação para lançamento do novo serviço. Conforme o processo avança, mais específicas e detalhadas vão se tornando as atividades. $\mathrm{O}$ conceito de serviço que se iniciou com uma necessidade de mercado, ainda abstrata, vai tomando forma e se consolidando em um novo serviço, com atividades, processos e recursos definidos, e pronto para ser lançado no mercado.

Tendo essa ferramenta desenvolvida, conseguimos visualizar quais são as principais entregas de cada fase do processo. Para avançar na análise, a próxima etapa consiste em identificar quais são as atividades-chave necessárias para que essas entregas sejam concluídas e quais os principais atores envolvidos nessas atividades. As atividades foram então mapeadas e codificadas, conforme demonstrado na tabela 3. 
Tabela 3: Códigos definidos para atividades-chave

\begin{tabular}{|c|c|c|c|c|c|c|c|c|c|c|c|}
\hline 1.1 .1 & $\begin{array}{l}\text { Pesquisa de Mercado } \\
\text { e Tendencias }\end{array}$ & 2.1 .1 & Sessões de brainstorming & 3.1 .1 & $\begin{array}{l}\text { Identificar areas e } \\
\text { pessoas envolvidas nos } \\
\text { processos }\end{array}$ & 4.1 .1 & $\begin{array}{l}\text { Identificar condições } \\
\text { para mitigar riscos em } \\
\text { teste piloto }\end{array}$ & 5.1 .1 & $\begin{array}{l}\text { Verificar se todas as } \\
\text { condições necessárias } \\
\text { para desenvolvimento }\end{array}$ & 6.1 .1 & $\begin{array}{l}\text { Avvaliar viabilidade de } \\
\text { expansão do Piloto }\end{array}$ \\
\hline 1.1 .2 & $\begin{array}{l}\text { Escutar o cliente } \\
\text { interno e externo }\end{array}$ & 2.1 .2 & $\begin{array}{l}\text { Realização de Grupos } \\
\text { Focais }\end{array}$ & 3.1 .2 & $\begin{array}{l}\text { Definir papéis e } \\
\text { responsáveis }\end{array}$ & 4.2 .1 & $\begin{array}{l}\text { Definir ambiente e } \\
\text { condições para Piloto }\end{array}$ & 5.2 .1 & $\begin{array}{l}\text { Implantação das } \\
\text { atividades previstas } \\
\text { emcronograma }\end{array}$ & 6.2 .1 & $\begin{array}{l}\text { Definit requisi tos para } \\
\text { expansão do Piloto }\end{array}$ \\
\hline 1.2 .1 & Desk research & 2.1 .3 & $\begin{array}{l}\text { Desenho de mapa de } \\
\text { requisitos }\end{array}$ & 3.1 .3 & $\begin{array}{l}\text { Reunião para ma peamento } \\
\text { de requisitos }\end{array}$ & 4.2 .2 & $\begin{array}{l}\text { Definir cronograma de } \\
\text { implantação do Piloto }\end{array}$ & 5.3 .1 & Ativação do Piloto & 6.3 .1 & $\begin{array}{l}\text { Ajuste nos processos } \\
\text { desenhados }\end{array}$ \\
\hline |1.2.2. & $\begin{array}{l}\text { Entrevistas para } \\
\text { entendimento da } \\
\text { demanda }\end{array}$ & 2.2 .1 & $\begin{array}{l}\text { Anali isar requisitos } \\
\text { mapeados }\end{array}$ & 3.2 .1 & Desenho de processos & 4.3 .1 & $\begin{array}{l}\text { Definir KPIs para } \\
\text { avaliação de } \\
\text { resultados }\end{array}$ & $\mid 5.3 .2$ & $\begin{array}{l}\text { Acompanhamento de } \\
\text { performance }\end{array}$ & 6.3 .2 & Treinamento de equipes \\
\hline 1.2 .3 & $\begin{array}{l}\text { Análise de dados } \\
\text { coletados }\end{array}$ & 2.2 .2 & $\begin{array}{l}\text { Definir funcionalides dos } \\
\text { requisitos }\end{array}$ & 3.3 .1 & $\begin{array}{l}\text { Avaliar recursose } \\
\text { irvestimentos necessários }\end{array}$ & 4.3 .2 & $\begin{array}{l}\text { Definir critérios de } \\
\text { aceitacão do Piloto }\end{array}$ & 5.3 .3 & Avaliação de riscos & 6.4 .1 & $\begin{array}{l}\text { Aprovação em Comitê } \\
\text { para Lancamento }\end{array}$ \\
\hline 1.2 .4 & $\begin{array}{l}\text { Definição de } \\
\text { oportunidade }\end{array}$ & 2.2 .3 & Priorizar requisitos & 3.3 .2 & $\begin{array}{l}\text { Construcão de Estudo de } \\
\text { Viabilidade }\end{array}$ & $4.3 .3 \mid$ & $\begin{array}{l}\text { Construir mapa de } \\
\text { riscos }\end{array}$ & 5.4 .1 & $\begin{array}{l}\text { Análise dos resul tados } \\
\text { obtidos }\end{array}$ & 6.4.1. & Disparo de tarefas \\
\hline 1.3 .1 & $\begin{array}{l}\text { Desenho de proposta } \\
\text { de valor }\end{array}$ & 2.3 .1 & $\begin{array}{l}\text { Desenhar a estrutura do } \\
\text { servicio }\end{array}$ & 3.4 .1 & $\begin{array}{l}\text { Aprovação de } \\
\text { Investimento }\end{array}$ & 4.4 .1 & Aprovação & & & 6.4 .1 . & $\begin{array}{l}\text { Comuric acacão de } \\
\text { Implantaçấo }\end{array}$ \\
\hline 1.4 .1 & $\begin{array}{l}\text { Validaçào da } \\
\text { eroposta_a. }\end{array}$ & 2.3 .2 & Construir business case & 3.4 .2 & $\begin{array}{l}\text { Aprovação do projeto } \\
\text { para implantacáo }\end{array}$ & & & & & & \\
\hline & & 4.1 & Alidação busit & & & & & & & & \\
\hline
\end{tabular}

Fonte: autor.

Com a lista de atividades, consolidou-se uma proposta de diagrama de fluxo para a empresa em estudo, apresentada na figura 3. Nessa figura, o eixo horizontal representa as etapas do ciclo de vida, e os blocos retangulares representam cada fase do método de engenharia de sistemas. As atividades-chave são representadas por círculos.

Figura 3 - Diagrama de fluxo para design e desenvolvimento de novos serviços

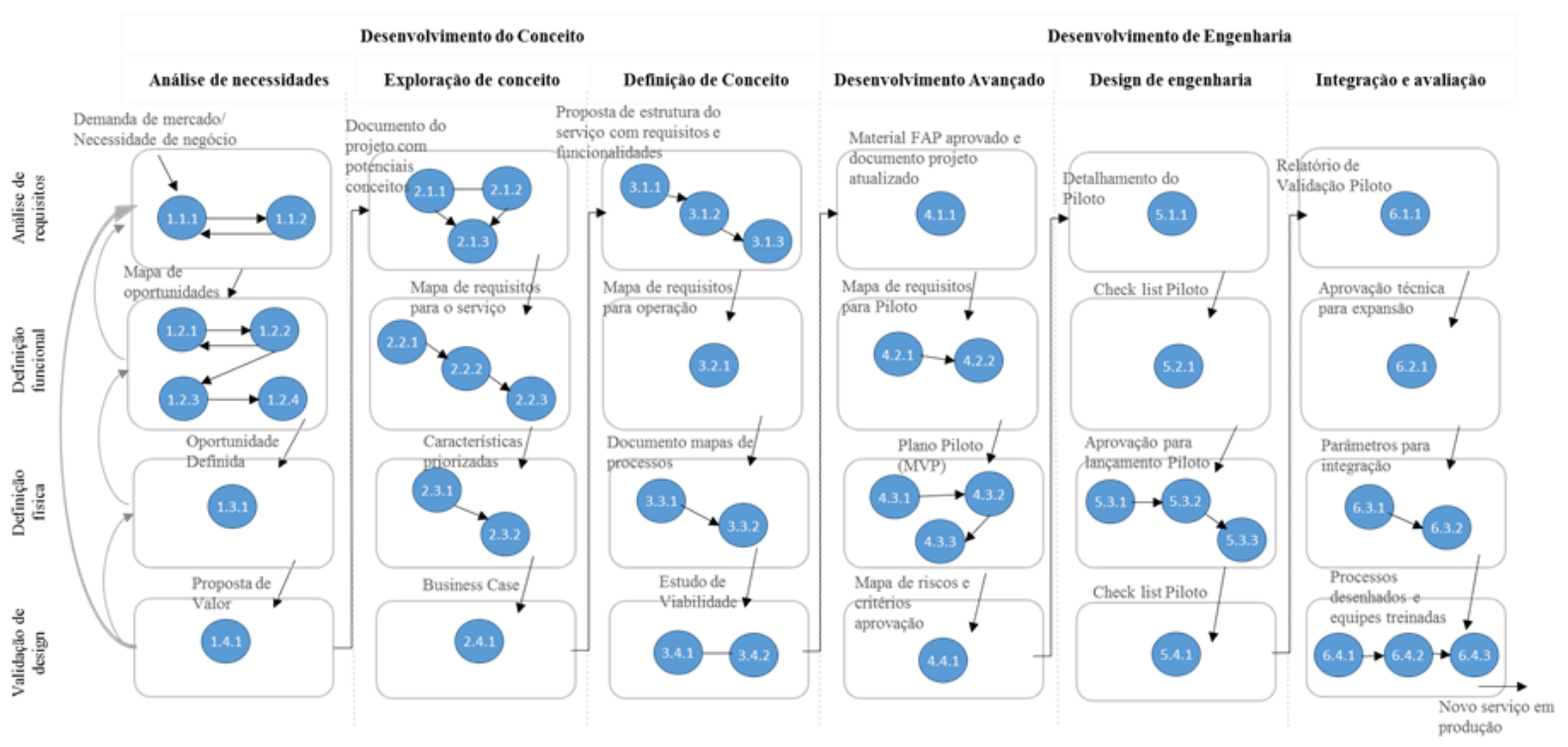

Fonte: autor.

Conhecendo as atividades-chave de cada etapa, foi desenhado um mapa com as áreas da empresa que participam do desenvolvimento da inovação, representado na figura 4. Nesse mapa estão representadas as áreas que executam as atividades, e as áreas de apoio à execução, indicadas por "Apoio- Nome da área". As áreas com estrutura dedicada à inovação estão realçadas no mapa. 
Figura 4 - Mapa de atores envolvidos no processo

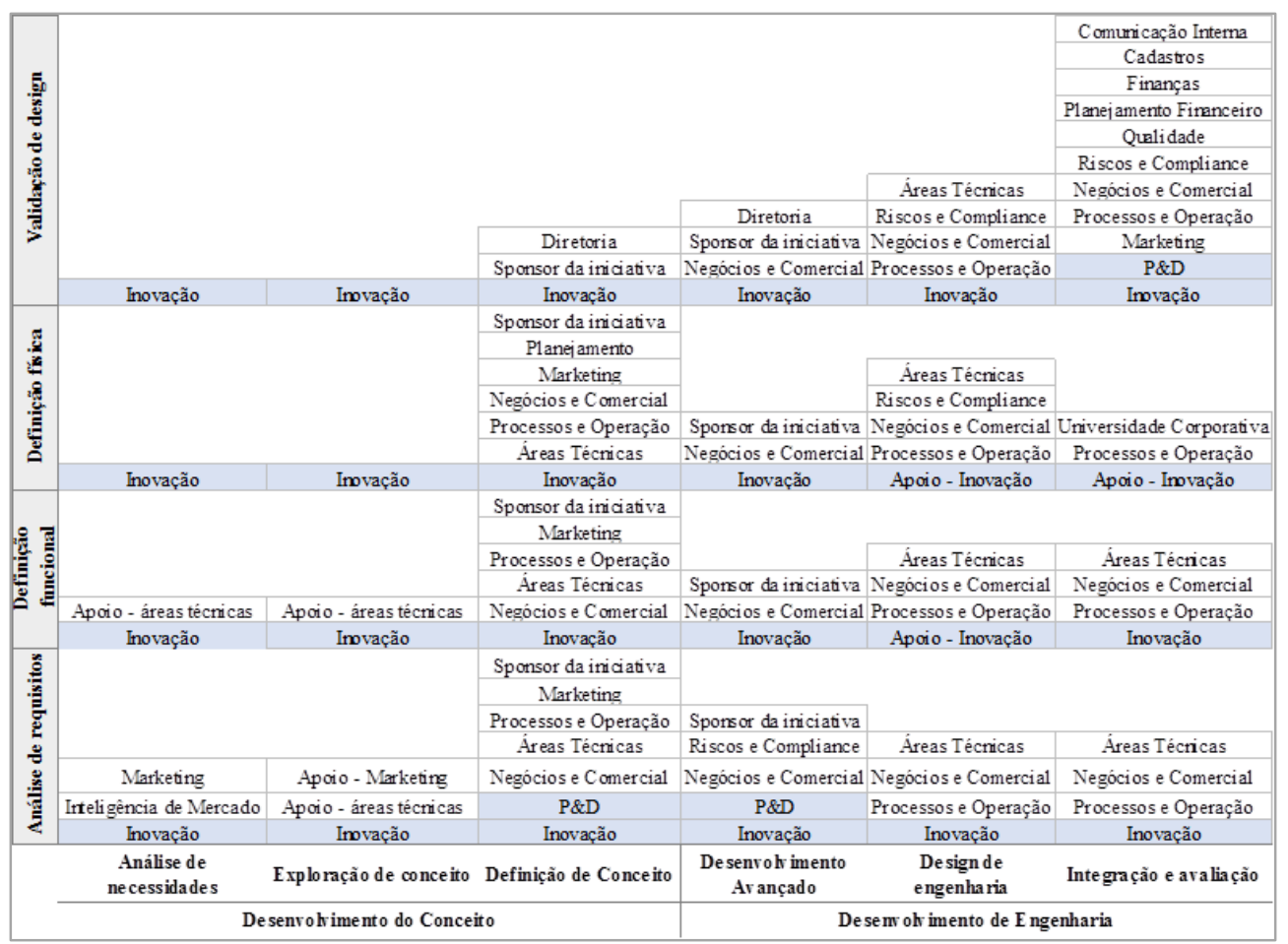

Fonte: autor.

O diagrama de fluxo elaborado, complementado a tabela construída a partir da aplicação do método de engenharia de sistemas no ciclo de vida, e ao mapa de atores do processo, fornece uma visão detalhada das etapas discorridas para o design e lançamento de um novo serviço e de quais atores devem ser envolvidos em cada uma delas. Assim, as informações são disponibilizadas aos gestores, para que possam aplicar as ferramentas de gestão e integração mais adequadas.

\section{CONCLUSÃO}

A figura 5 representa o processo desenhado na empresa para design e implantação de novos serviços. Esse modelo apresenta as macro etapas realizadas, entretanto, não traz a dimensão de complexidade dos processos e atividades que são desenvolvidas em cada uma dessas etapas.

Figura 5- Processo de novos serviços da empresa foco de estudo

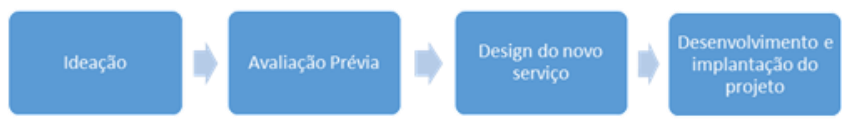

Fonte: autor

A aplicação do método de engenharia de sistemas no ciclo de vida do sistema, detalhada nesse artigo, demonstra que uma ferramenta de engenharia pode ser aplicada à gestão de inovação, trazendo uma visão mais clara e detalhada dos processos necessários ao design e desenvolvimento de um novo serviço. Essa ferramenta traz aos gestores de inovação informações relevantes para auxiliá-los na materialização de um novo conceito de serviço, uma vez que ela pré-determina o caminho que uma ideia poderá percorrer até ser implantada, antecipando a integração que deverá ocorrer entre os vários atores, transformando o que era desconhecido em conhecido e, por fim, diminuindo os riscos do processo. 
Esse artigo alcançou seu objetivo ao demonstrar a aplicação de uma ferramenta de engenharia para complementar a gestão de inovação em uma empresa de medicina diagnóstica. Os resultados sugerem que seu uso possa auxiliar a integração entre as diversas unidades de negócio envolvidas no processo, entretanto, essa validação ainda não está concluída. Para tal faz-se necessário a aplicação da ferramenta na empresa, como apoio para o desenvolvimento de um novo conceito de serviço.

Sugere-se que a metodologia aplicada possa ser projetada para outras empresas, e também para novos conceitos de produtos e modelos de negócios. Como passos subsequentes a esse estudo, sugere-se a ampliação da amostra analisada para outros tipos de inovação, e a análise de quais mecanismos de integração podem ser mais efetivos, de acordo com fluxo detalhado.

\section{REFERÊNCIAS}

CHAVES, C.V.; ALBUQUERQUE, E.M.. Desconexão no sistema de inovação no setor saúde: uma avaliação preliminar do caso brasileiro a partir de estatísticas de patentes e artigos. Economia Aplicada, Ribeirão Preto , v. 10, n. 4, p. 523-539, 2006.

CURTIS, L.H., SCHULMAN, K.A. Overregulation of healthcare: musings on disruptive innovation theory. Law Contemp. Probl, 69(4):195-206, 2006.

HERZLINGER, R.E. Why innovation in healthcare is so hard. Harvard Business Review, Mai2006

KOSSIAKOFF, A. et. Al. Systems engineering: principles and practice. 2.ed. New Jersey: John Wiley \& Sons, Inc., 2011.

LISCHKA, J.A. Pressure and organizational change in the digital age. Working Paper. Reuters Institute for the Study of Journalism, University of Oxford, 2015.

MARCH J. Exploration and exploitation in organizational learning. Organization Science, 2: 71-87. 1991.

MARKIDES, C.; CHU W. Innovation through ambidexterity: how to achieve the ambidextrous organization. In Costanzo L and MacKay B eds., Handbook of research on strategy and foresight, Elgar, 2009

MARRONE, P.V. (Coord.). Saúde 4.0- Propostas para impulsionar o ciclo das inovações em dispositivos médicos (DMAs) no Brasil. São Paulo: ABIIS, 2015.

OLIVER, J. J. Dynamic capabilities and adaptive advantage in UK media. In: LISCHKA, J.A. Pressure and organizational change in the digital age. Working Paper. Reuters Institute for the Study of Journalism, University of Oxford, 2015

TEH, C.C. A influência das tensões ambidestras na arquitetura organizacional para inovação: estudo de casos em empresas brasileiras da indústria de transformação. Escola Politécnica da USP. Departamento de Engenharia de Produção. 242 p. São Paulo, 2014. Tese (Doutorado)

TUSHMAN, M. L. and O'REILLY, C.A.. The ambidextrous organization: managing evolutionary and revolutionary change. California Management Review, 38: 1-23. 1996

TUSHMAN, M. L. and O'REILLY, C.A.. The ambidextrous organization. Harvard Business Review 82, n.4, p. 74-81, apr 2004.

TUSHMAN, M. L. and O'REILLY, C.A.. Leading strategic renewal: Proactive punctuated change through innovation streams and disciplined learning. Paper presented at the Harvard Business School, 2013. 